\title{
Construction of micro-branched crosslink fluorinated polyimide with ultra-low dielectric permittivity and enhanced mechanical properties
}

\author{
Wanjing Zhao ${ }^{1}$, Xianwu Cao ${ }^{1}$, Jinshu Huang ${ }^{1}$, Jiangwei Wen ${ }^{1}$, Yun He ${ }^{2}$, Junwei Zha ${ }^{3}$, \\ Robert Kwok Yiu $\mathrm{Li}^{2}{ }^{\text {(1) }}$, Wei $\mathrm{Wu}^{1,2^{*} \text { (1) }}$ \\ ${ }^{1}$ National Engineering Research Center of Novel Equipment for Polymer Processing, Key Laboratory of Polymer \\ Processing Engineering of Ministry of Education, Guangdong Provincial Key Laboratory of Technique and Equipment \\ for Macromolecular Advanced Manufacturing, School of Mechanical and Automotive Engineering, South China \\ University of Technology, 510640 Guangzhou, China \\ ${ }^{2}$ Department of Materials Science and Engineering, City University of Hong Kong, Tat Chee Avenue, Kowloon, \\ Hong Kong SAR, China \\ ${ }^{3}$ School of Chemistry and Biological Engineering, University of Science \& Technology Beijing, 100083 Beijing, China
}

\begin{abstract}
There is a great demand for low dielectric materials as insulating interlayers in large-scale integrated circuit development. However, it is still a huge challenge to reduce the dielectric permittivity of polymers while maintaining excellent thermal stability and mechanical properties. In this work, the fluorinated polyimides (PIs) in combination with a micro-branched crosslinking structure were prepared successfully by introducing different amounts of 1,3,5-tris(4-aminophenyl) benzene (TAPB) to obtain ultra-low dielectric permittivity. The results revealed that PI film containing 2 mmol TAPB had the lowest dielectric permittivity (2.47) and dielectric loss $(0.008)$ at $1 \mathrm{MHz}$ due to the fluorine atoms and the micro-branched crosslink structure, which not only decreased the molecular polarizability but also increased the free fractional volume. In addition, PI film containing 2 mmol TAPB had the highest tensile strength of $106.02 \mathrm{MPa}$ with an elongation at a break of $15.1 \%$ because the presence of TAPB effectively promoted the connection between PI molecular chains, resulting in the inhibition of the molecular mobility. The incorporation of TAPB also enhanced the thermal stability and ultraviolet light-shielding performance of PI films. This method paves the way for the development of PIs with ultra-low dielectric permittivity for the electronic industry.
\end{abstract}

Keywords: polyimide, micro-branched, crosslinking, dielectric permittivity, mechanical properties

\section{Introduction}

With the rapid advent of the fifth-generation $(5 \mathrm{G})$ mobile communication era, the fast development of large-scale integrated circuits has created an urgent demand for the high performance of interlayer media [1]. However, the resistance-capacitance time delay, the crosstalk noise between lines, and the power dissipation in devices have become the primary bottlenecks in integrated circuit development [2,3]. Therefore, there is a great demand for low dielectric materials as insulating interlayers with good thermal resistance, low water absorption, and excellent mechanical properties for microelectronics. However, the dielectric constant of traditional aromatic polyimides (PIs) generally range from 3.0 to 3.6, which is difficult to meet the requirements of the next generation of interlayer dielectrics [4].

Extensive research has demonstrated that the incorporation of large rigid groups, fluorinated groups, and non-coplanar structures can increase the free 
fractional volume (FFV) of the molecular chain and/or reduce the molecular polarizability, thus reducing the dielectric constant of materials. Wang et al. [5] found that the introduction of trifluoromethyl as a side group of PI decreased the dielectric permittivity from 3.0 to 2.48 at $10 \mathrm{GHz}$, which was ascribed to the increasing of the free volume fraction, resulting in the looser packing of polymer chains and lower electronic polarizability. In addition, the presence of fluorine-containing groups could endow aromatic PIs with good moisture resistance and excellent solubility. The hydrophobicity of the PI films was improved because the introduced fluorine atoms could reduce the surface energy of the films [6]. The contact angle of the PI film increased from 83.7 to $116.0^{\circ}$ when 30 mol\% 2,2-bis-(trifluoro methyl)-4,40-diaminobiphenyl (TFMB) was added [7]. In addition, introducing air into PI film is another way to reduce the dielectric constant. Cao et al. [8] found that the PI composites with $8 \mathrm{wt} \% \mathrm{KH} 560$ modified hollow glass microspheres (HGM) achieved the low dielectric constant of 2.21 and the dielectric loss of 0.0059 at $1 \mathrm{MHz}$. The porous PI film could also be prepared by electrophoresis deposition of PI nanoparticles, and the air voids were generated by the PI nanoparticles themselves [9] Chen et al. [10] introduced polyethylene glycol (PEG) into the graphene fluoroxide/ polyimide (GFO/PI). The result showed porous GFO/ PI obtained a very low dielectric constant of 2.29 due to PEG decomposition, which hindered the agglomeration of GFO nanosheets and generated micro-pores in the PI matrix during thermal imidization.

Recently, the introduction of crosslinked structures into PIs has received considerable attention because this method can simultaneously reduce the dielectric constant and maintain comprehensive properties. the PI/TAPOB hybrid film was decreased from 3.42 to $3.12(10 \mathrm{MHz})$ as compared to that of neat PI due to the induced micro-branched crosslink structure could bring in a higher free volume of the molecular chain. In addition, the presence of micro-branched structures in PIs could also increase the rigidity of the PI chains to improve the resistance to deformation of PI films simultaneously [12]. Song et al. [13] found the contact angle values of PI films increased, indicating that the surface of PI films became more hydrophobic due to the existence of crosslinked networks.

In this paper, a novel type of fluorinated PI was copolymerized based on the 1,3-bis(4-aminophenoxy) benzene (TPE-R), 4,4'-(9-fluorenylidene)dianiline (BAFL) as the diamine monomers, and 4,4'-(hexafluoroisopropylidene)diphthalic anhydride (6FDA) and 2,2-bis(4-(3,4-dicarboxyphenoxy)phenyl)propane dianhydride (BPADA) as the dianhydride monomers. Furthermore, the cross-linker agent 1,3,5-tris(4aminophenyl)benzene (TAPB) was used to endow the as-prepared PIs with a micro-branched structure. It was expected that the combination of the fluorinecontaining groups and the micro-branched structure could effectively reduce the dielectric permittivity of PIs as well as improve the mechanical properties. The effects of TAPB content on thermal stability, hydrophobicity, dielectric, and mechanical properties were also systematically discussed.

\section{Experimental section}

\subsection{Materials}

4,4'-(Hexafluoroisopropylidene) diphthalic anhydride (6FDA), 1,3-bis(4-aminophenoxy)benzene (TPE-R), 4,4'-(9-fluorenylidene)dianiline (BAFL), 2,2-bis[4(3,4-dicarboxyphenoxy)phenyl]propane dianhydride (BPADA), and 1,3,5-tris(4-aminophenyl)benzene (TAPB) were purchased from Bepharm (Shanghai China). $N, N$-Dimethylacetamide (DMAc, $99.5 \%$ ) was purchased from Tianjin Fuyu fine chemical Co., Ltd (Tianjin, China). Prior to preparation, the four monomers were dried to remove moisture, and the DMAc was dewatered and stored in a sealed container for later use.

\subsection{Synthesis of cross-liked PIs}

Firstly, the calculated two diamines (BAFL and TPE-R) and the appropriate amount of DMAc were added into the three-necked flask under the protection of nitrogen, which weredissolved under mechanical stirring at room temperature. After the diamine was completely dissolved, the three-necked flask was moved to an ice-water mixing bath; BPADA and 6FDA were introduced into the threenecked flask and added to an appropriate amount of DMAc solvent to make the $15 \mathrm{wt} \%$ solid content of the solution. After 4 hours of reaction, a certain amount of TAPB was added to the three-necked flask and kept stirring for $1 \mathrm{~h}$.

When the reaction was completed, the solution became more viscous. After the bubbles in the glue were removed, a film coater was used to coat the resulting glue on the glass plate and then put the glass plate in an oven for thermal imidization. The heating 
Table 1. Formulations and physical properties of PIs.

\begin{tabular}{|c|c|c|c|c|c|c|}
\hline Samples & $\begin{array}{c}\text { TPE-R } \\
{[\mathbf{m m o l}]}\end{array}$ & $\begin{array}{c}\text { BAFL } \\
{[\mathbf{m m o l}]}\end{array}$ & $\begin{array}{c}\text { BPADA } \\
{[\mathbf{m m o l}]}\end{array}$ & $\begin{array}{c}\text { 6FDA } \\
{[\mathbf{m m o l}]}\end{array}$ & $\begin{array}{c}\text { TAPB } \\
{[\mathbf{m m o l}]}\end{array}$ & $\begin{array}{c}\text { Density } \\
{\left[\mathbf{g} \cdot \mathbf{c m}^{-3}\right]}\end{array}$ \\
\hline PI-0 & 3 & 3 & 3 & 3 & 0 & 1.495 \\
\hline PI-1 & 3 & 3 & 3 & 3 & 0.1 & 1.340 \\
\hline PI-1.5 & 3 & 3 & 3 & 3 & 0.15 & 1.276 \\
\hline PI-2 & 3 & 3 & 3 & 3 & 0.2 & 1.245 \\
\hline PI-2.5 & 3 & 3 & 3 & 3 & 0.25 & 1.466 \\
\hline PI-3 & 3 & 3 & 3 & 3 & 0.3 & 1.570 \\
\hline PI-4 & 3 & 3 & 3 & 3 & 0.4 & 1.595 \\
\hline
\end{tabular}

program for thermal imidization was as follows: $80^{\circ} \mathrm{C}$ for $2 \mathrm{~h}, 100^{\circ} \mathrm{C}$ for $1 \mathrm{~h}, 150^{\circ} \mathrm{C}$ for $1 \mathrm{~h}, 200^{\circ} \mathrm{C}$ for $1 \mathrm{~h}, 250^{\circ} \mathrm{C}$ for $1 \mathrm{~h}$, and $300^{\circ} \mathrm{C}$ for $1 \mathrm{~h}$. After the thermal imidization heating program was completed, the glass plate was put in warm water to remove the film, and the PI/TAPB composite film was dried. The formulations of the prepared PIs are shown in Table 1.

\subsection{Characterization}

Attenuated total reflectance infrared spectroscopy (ATR-FTIR, Nexus 670, Thermo Nicolet, USA) was used to detect the functional group in the range of $400-4000 \mathrm{~cm}^{-1}$ and 32 scans. The X-ray diffractometer (XRD, X 'Pert3 POWDER, Panaco, Netherlands) was used for the X-ray analysis with $\mathrm{Cu} K_{\alpha}$ radiation $(\lambda=0.154 \mathrm{~nm})$. The morphologies of the samples were characterized using a scanning electron microscope (SEM, Quanta 250, FEI Corporation, USA). Dynamic mechanical, thermal analysis was performed with a dynamic thermomechanical analyzer (DMA, DMA242 Eartemis, Netzsch, Germany) in tensile mode. The specimens were measured at a ramping rate of $10^{\circ} \mathrm{C} \cdot \mathrm{min}^{-1}$ with a fixed frequency of $1 \mathrm{~Hz}$ in nitrogen. Thermogravimetric analysis (TGA) was performed with a thermogravimetric analyzer (TGA, TG209F3, Netzsch, Germany) from 30 to $800^{\circ} \mathrm{C}$ at a heating rate of $10^{\circ} \mathrm{C} \cdot \mathrm{min}^{-1}$ in a nitrogen atmosphere. The crystallization behavior of PI films was analyzed by differential scanning calorimetry (DSC, NETZSCH DSC-204F1) at a scanning rate of $20{ }^{\circ} \mathrm{C} \cdot \mathrm{min}^{-1}$ in nitrogen. A surface contact angle measuring instrument (OCA40 Micro, Dataphysics, German) was used to evaluate the hydrophobicity of the samples at room temperature. The PI films were spread on a slide, and a $0.2 \mathrm{ml}$ droplet of deionized water was dropped onto the films, and contact angle values were obtained by averaging five measurement values on different areas of the film surface. Dielectric performance was measured by a precision impedance analyzer (WK6500B, Stabilizer, UK) at room temperature in the frequency range between $10^{2}$ and $10^{7} \mathrm{~Hz}$. The UV-Vis spectra of PI films were evaluated by a Hitachi U3900 spectrophotometer. To measure the tensile properties of the PI films, specimens were cut into sheets with a width of $10 \mathrm{~mm}$ and tested on a universal testing machine (Instron 5566, USA).

\section{Results and discussion}

The synthesized route of the fluorinated copolymerized polyimide with a micro-branched structure is shown in Figure 1. Two types of diamines (BAFL and TPE-R) and two types of dianhydride (BPADA and 6FDA) were utilized to synthesize quaternary fluorinated polyimide by copolymerization under the protection of nitrogen. Then, TAPB was added into the PAA solution as a crosslinking agent to form the branched crosslinked PI. The various types of obtained PIs are presented in Figure 1.

The structure of the prepared PI films was characterized by ATR-FTIR analysis. As shown in Figure 2a, the characteristic peaks of the $\mathrm{C}=\mathrm{O}$ group appear at 1777 and $1718 \mathrm{~cm}^{-1}$, corresponding to the asymmetric stretching vibration and the symmetric stretching vibration, respectively [14]. The characteristic peaks of the aromatic imide group are located at 1366 and $716 \mathrm{~cm}^{-1}$. The former band is attributed to the stretching vibration of the $\mathrm{C}-\mathrm{N}$ group, whereas the latter one is ascribed to the bending vibration of the $\mathrm{C}=\mathrm{O}$ group. All the results indicate the completion of thermal amination [15]. However, there is no change in FTIR after adding TAPB due to the $\mathrm{C}-\mathrm{N}$ peak of TAPB overlapping with the $\mathrm{C}-\mathrm{N}$ peak of the imide group at $1366 \mathrm{~cm}^{-1}$ in pure period [16]. The XRD patterns were utilized to explore the molecular packing preferences of PI films. As shown in Figure 2b, all the PI films exhibit a wide diffraction peak around $2 \theta=10-20^{\circ}$, which is characteristic diffraction of typical amorphous PI. The result indicates that the 
PI films are amorphous aggregate structures due to Moreover, the introduction of the trifluoromethyl the PI copolymerization process was random [17]. groups and flexible ether bonds resulted in the loose

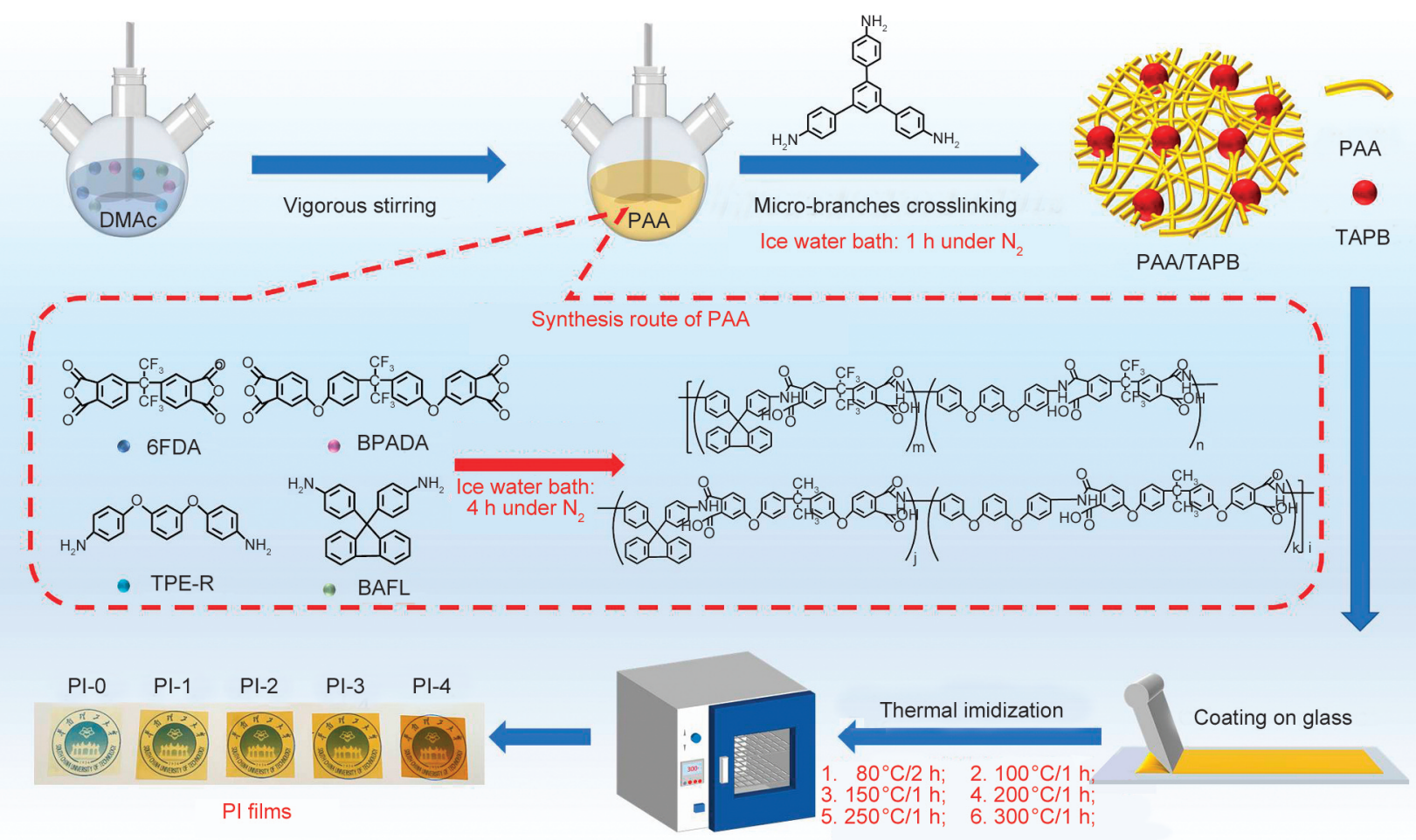

Figure 1. Synthesis route of fluorinated polyimide with micro-branched crosslinking structure.
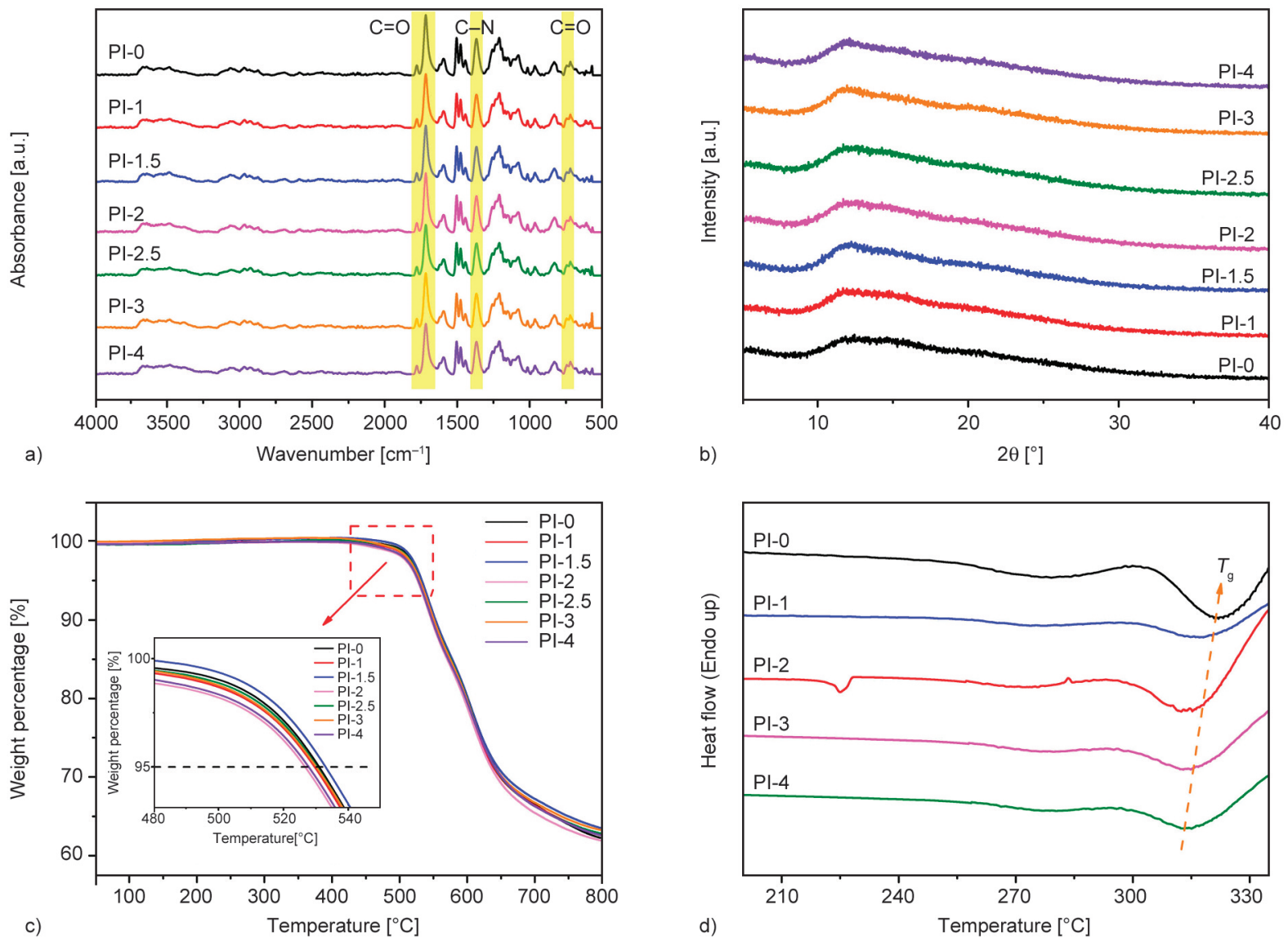

Figure 2. (a) ATR-FTIR spectra, (b) XRD patterns, (c) TGA curves, and (d) DSC heating curves of PIs. 
chain stacking density of PI molecular chains [18]. The TGA curves of the PI films are shown in Figure 2c. The corresponding TGA data, including the temperatures corresponding to $5 \mathrm{wt} \%$ weight loss $\left(T_{5}\right)$, the peak temperatures corresponding to the maximum weight loss rate $\left(T_{\mathrm{p}}\right)$, and the char residues at $800^{\circ} \mathrm{C}$, are listed in Table 2 . It is clearly observed that the $T_{5}$ values of all the PIs are higher than $527^{\circ} \mathrm{C}$, and the $T_{\mathrm{p}}$ shows a slight increase after the incorporation of TAPB. In addition, the residues of PI films at $800^{\circ} \mathrm{C}$ are all higher than $60 \%$. The above results indicate that PI films have excellent thermal stability, and the branched crosslinked structure has little effect on the thermal stability performance. The DSC analysis revealed that the glass transition temperature $\left(T_{\mathrm{g}}\right)$ of PIs with the increase of TAPB content from 0 to $4 \mathrm{mmol}$. As shown in Figure 2d, all of the PIs exhibit super high $T_{\mathrm{g}}\left(313^{\circ} \mathrm{C}\right)$, which indicates the excellent thermal stability of PIs. However, $T_{\mathrm{g}}$ decreased slightly with the increasing TAPB content compared with pure PI. It may be speculated that the introduction of TAPB expanded the intermolecular distance, which improved the flexibility of the molecular chain of PIs, resulting in the $T_{\mathrm{g}}$ being reduced slightly.

The hydrophobic property of PI films was measured by the water contact angle. As shown in Figure 3, the contact angle value of pure PI is about $87.0^{\circ}$ due to the introduction of fluorine atoms can decrease the surface energy of the material and improve the hydrophobicity of PIs [19]. Compared with pure PI, the contact angle of PIs containing TAPB increases from 72.9 to $95.1^{\circ}$ and then decreases slightly. The increase in contact angle indicates the hydrophobicity of the films has improved, which is beneficial to a lower moisture absorption rate, resulting in the longterm stability of the film in the service environment. This is because a certain content of TAPB promotes

Table 2. Thermal properties of PIs.

\begin{tabular}{|c|c|c|c|c|c|}
\hline \multirow[b]{2}{*}{ Samples } & \multicolumn{3}{|c|}{ TGA } & \multirow{2}{*}{$\begin{array}{c}\text { DSC } \\
\begin{array}{c}T_{\mathrm{g}} \\
{\left[{ }^{\circ} \mathrm{C}\right]}\end{array}\end{array}$} & \multirow{2}{*}{$\begin{array}{c}\text { DMA } \\
T_{\mathrm{g}} \\
{\left[{ }^{\circ} \mathbf{C}\right]}\end{array}$} \\
\hline & $\begin{array}{c}T_{5} \\
{\left[{ }^{\circ} \mathbf{C}\right]}\end{array}$ & $\begin{array}{c}T_{\mathbf{p}} \\
{\left[{ }^{\circ} \mathbf{C}\right]}\end{array}$ & $\begin{array}{c}\text { Residues at } \\
800^{\circ} \mathrm{C} \\
{[\mathrm{wt} \%]}\end{array}$ & & \\
\hline PI-0 & 531.3 & 538.4 & 62.2 & 322.7 & 272.9 \\
\hline PI-1 & 529.6 & 545.1 & 62.7 & 316.6 & 276.7 \\
\hline PI-1.5 & 533.0 & 541.6 & 63.5 & - & - \\
\hline PI-2 & 527.2 & 539.8 & 61.9 & 313.7 & 275.6 \\
\hline PI-2.5 & 530.6 & 542.6 & 62.8 & - & - \\
\hline PI-3 & 530.4 & 543.2 & 63.2 & 314.5 & 278.1 \\
\hline PI-4 & 528.2 & 541.3 & 62.6 & 314.8 & 283.5 \\
\hline
\end{tabular}

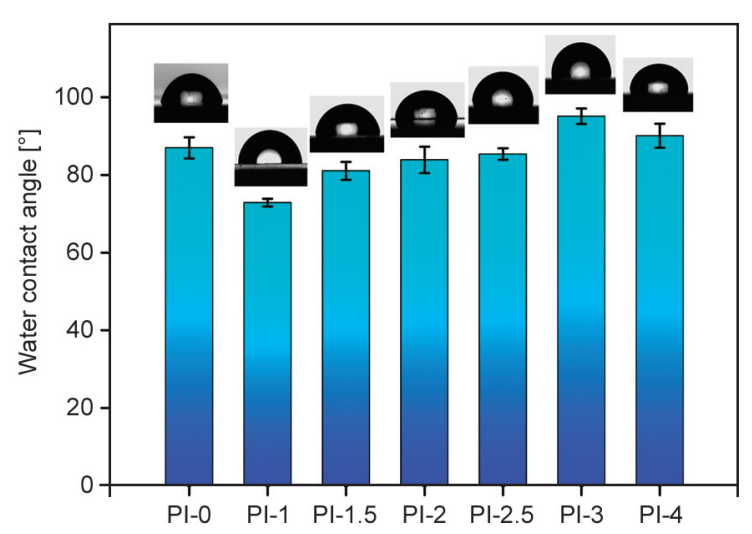

Figure 3. Water contact angle on the surfaces (Inserts are the contact angle images).

the formation of crosslink networks, which decrease the distance between the molecules and prevents water from entering the molecular chains. However, excessive addition of TAPB leads to incomplete amino reactions, so the hydrophobicity of the films was reduced [20]. Therefore, the fluorinated groups and crosslinked structure contribute to the enhancement of the hydrophobicity of PIs.

The ultraviolet-visible light (UV-Vis) spectra of the PI films are shown in Figure 4. The curves in Figure 4 show that the light transmittance of the nanocomposite films gradually decreased with the increase of TAPB content at the wavelength of 350-800 nm. With the addition of $2 \mathrm{wt} \%$ TAPB, the PI- 2 film could absorb the full band of UV light. In addition, the transmittance of PI films decreased from 87.2 to $68.4 \%$ at a $600 \mathrm{~nm}$ light wavelength. The photographs of PI films in Figure 1 exhibit that the color of five PI films turns deep yellow with the increase of TAPB content. This is because the charge transfers from the electron donor (diamine) to the electron

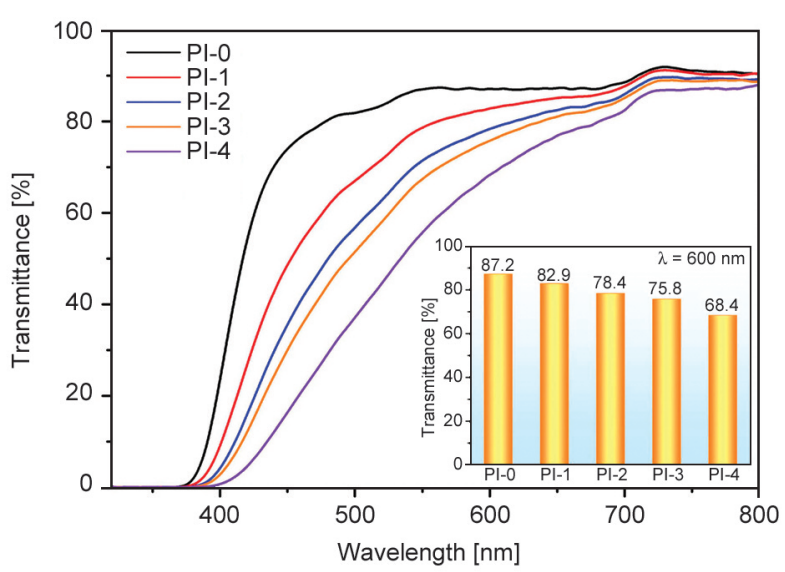

Figure 4. UV-Vis spectra of the PI films Insert is the transmittance of the prepared polyimide films under $600 \mathrm{~nm}$ wavelength. 
acceptor (dianhydride) in PI molecule chains, resulting in the formation of an intermolecular charge transfer complex (CTC). In the case of PI-0, the presence of trifluoromethyl groups has strong steric hindrance and electron absorption effects that inhibit the formation of intermolecular CTC [21]. However, the introduction of TAPB would improve the absorption of visible light of PI films because TAPB has electronrich diamine groups and strong electron-donating ability, resulting in a stronger CTC effect [22].

The variation curves of the dielectric permittivity $\left(\varepsilon_{\mathrm{r}}\right)$ and dielectric loss $(\tan \delta)$ of PI films at the frequency range of $10^{2}-10^{7} \mathrm{~Hz}$ are shown in Figure 5. It is noted that the dielectric permittivity of PI films in Figure $5 \mathrm{a}, 5 \mathrm{~b}$ is significantly reduced by the introduction of TAPB, and the dielectric loss is mainmittivity and dielectric loss change slightly at low frequency because the orientations of most dipoles can follow the variation speed of the applied electric field at a low-frequency range. With the frequency increasing, the dipole orientations can hardly catch up with the change of the applied field, which results in the reduction of dielectric permittivity and the rapid

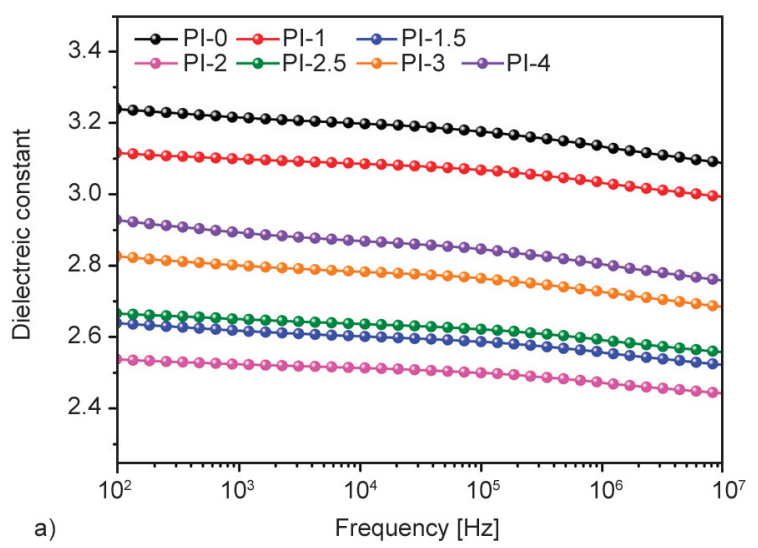
tained at a low level. In addition, the dielectric per-

increase of $\tan \delta$. As plotted in Figure $5 \mathrm{c}$, the dielectric permittivity of PIs reached the lowest values at $0.2 \mathrm{mmol}$ content of TAPB under $1 \mathrm{MHz}$ and then increased with the further addition of TAPB. Compared with pure PI, the dielectric permittivity of PI-2 is reduced from 3.13 to 2.47 at $1 \mathrm{MHz}$, and the dielectric loss exhibits a $10.3 \%$ reduction. It is attributed to the introduction of TAPB in an appropriate amount to form a micro-branched structure to expand the space between the molecular chains. The expanded FFV leads to a remarkable reduction in dielectric permittivity. Furthermore, the density of PIs decreased at first and then increased, and the PI-2 has the lowest density in Table 1, which is consistent with the dielectric permittivity. It indicates that the micro-branched structure widens the distance between molecules and reduces the aggregation of molecular chains, resulting in the reduction of the dielectric permittivity. Meanwhile, the formation of the slight crosslinked network structure will restrict the orientation of dipoles effectively to reduce molecular polarizability, which also leads to the reduction of dielectric permittivity [12]. When the content of TAPB exceeded $0.2 \mathrm{mmol}$, the dielectric permittivity

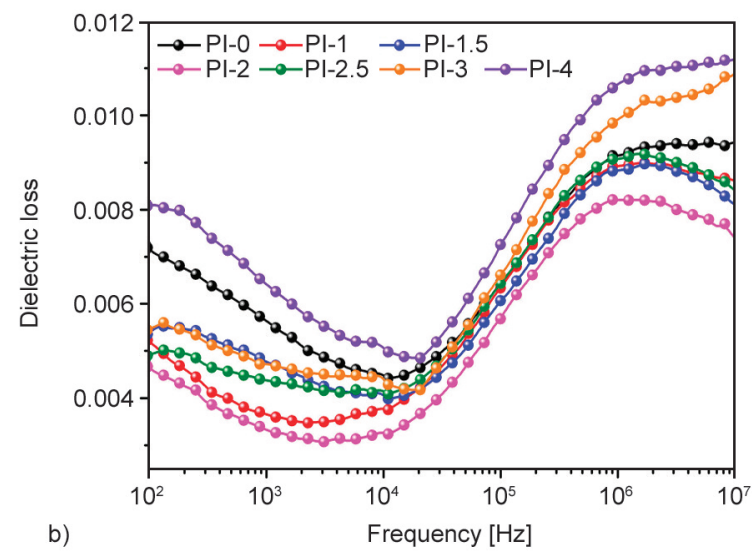

b)

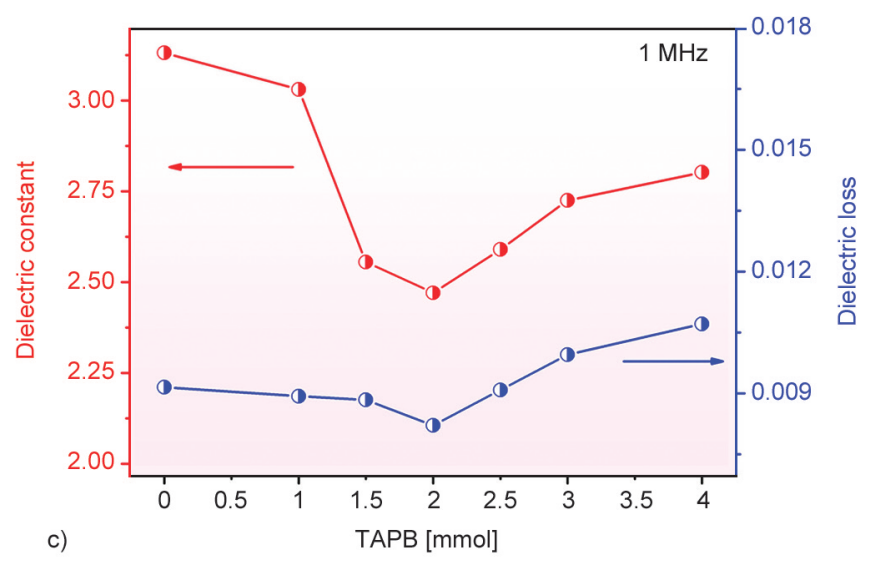

Figure 5. (a) Dielectric constant, (b) dielectric loss as a function of the frequency of PIs, and (c) dielectric constant and loss with different TAPB content under $1 \mathrm{MHz}$. 
Table 3. Comparison of dielectric properties of different modified polyimides.

\begin{tabular}{|c|c|c|c|c|c|}
\hline PIs & $\begin{array}{c}\text { Dielectric } \\
\text { permittivity }\end{array}$ & $\begin{array}{c}\text { Dielectric } \\
\text { loss }\end{array}$ & Filler content & $\begin{array}{c}\text { Frequency } \\
{[\mathrm{MHz}]}\end{array}$ & References \\
\hline Fluorinated graphene $(\mathrm{FG}) /$ polyimide & 2.64 & 1.7600 & $0.5 \mathrm{wt} \% \mathrm{FG}$ & 1 & [4] \\
\hline Fluorinated polyimide/POSS & 2.90 & 0.0130 & $8 \mathrm{wt} \%$ POSS & 1 & [23] \\
\hline Fluorinated polyimide/POSS & 2.90 & - & $0.35 \mathrm{wt} \%$ POSS & 1 & [24] \\
\hline $\begin{array}{l}\text { Fluorinated polyimide/ } \\
\text { 1,3,5-tris(4-aminophenoxy)benzene (TAPOB) }\end{array}$ & 3.12 & 0.0060 & $0.15 \mathrm{mmol}$ TAPOB & 1 & [11] \\
\hline OAPS-GO/PI & 2.90 & - & $0.5 \mathrm{wt} \% \mathrm{GO}$ & 100 & [25] \\
\hline $\mathrm{PI} /$ Cardo-containing diluent & 2.65 & 0.0350 & $20 \mathrm{wt} \%$ cardo containing diluent & 200 & [26] \\
\hline $\mathrm{PI} / \mathrm{HGM}$ & 3.00 & 0.0060 & $8 \mathrm{wt} \% \mathrm{HGM}$ & 1 & [8] \\
\hline 0CN-6FDA & 3.20 & 0.0750 & - & 1 & [27] \\
\hline 2CN-6FDA & 3.50 & 0.7000 & - & 1 & [27] \\
\hline Porous fluorine-containing PI(P-FPI) & 2.80 & 0.0025 & - & 1 & [19] \\
\hline P-POSS-PIs & 2.65 & 0.0075 & $10 \mathrm{wt} \%$ POSS & 1 & [19] \\
\hline Poly(benzoxazole-co-imide) (PI-co-PBO-X) & 3.20 & 0.0300 & $10 \mathrm{~mol} \% \mathrm{APAF}$ & 100 & [28] \\
\hline Polyimide/POSS & 5.25 & 0.0150 & $0.162 \mathrm{~g}$ of POSS & 1 & [29] \\
\hline Polyimide $/ \mathrm{SiO}_{2}$ hollow spheres & 3.00 & 0.0028 & $3 \mathrm{wt} \% \mathrm{SiO}_{2}$ & $10^{-1}$ & [30] \\
\hline Fluorinated Polyimide/TAPB & 2.47 & 0.0080 & $2 \mathrm{mmol}$ TAPB & 1 & This work \\
\hline
\end{tabular}

and loss started to increase due to the excess TAPB content, which can diminish the distance between molecular chains via the crosslinking effect. Thus, the dominant crosslinking effect will greatly offset the effect of the micro-branched on increasing FFV, resulting in a decrease in FFV and an increase in dielectric permittivity [11]. The comparison of the dielectric properties of different fluorinated polyimides is shown in Table 3.

DMA is used to investigate the storage modulus $\left(E^{\prime}\right)$ and loss factor $(\tan \delta)$ of the PIs with different TAPB contents, as shown in Figure 6. The temperature corresponding to the peak of $\tan \delta$ is usually defined as the glass transition temperature $\left(T_{\mathrm{g}}\right)$ of PI (Table 2), which is more sensitive to the change of $T_{\mathrm{g}}$ values obtained from DSC. As shown in Figure 6a, the storage modulus of PIs reduces gradually with rising

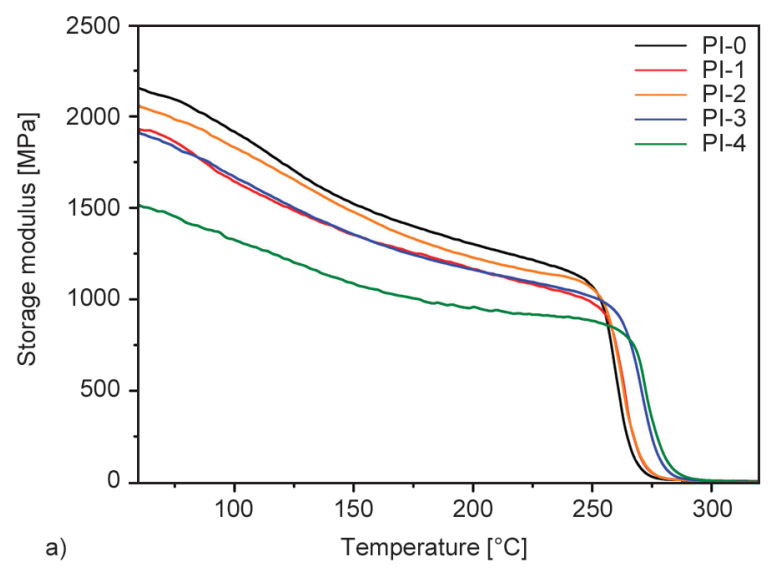

temperature and drops sharply near the $T_{\mathrm{g}}$. In Figure $6 \mathrm{~b}$, the $T_{\mathrm{g}}$ of PIs increases from 272.9 to $283.5^{\circ} \mathrm{C}$ with the content of TAPB increasing due to the crosslinked network hindering the movement of molecular chains, resulting in the improvement of the heat resistance [12].

Figure 7 shows the variation of tensile strength and elongation at the break of PI films with TAPB content increasing. The tensile strength of PI films exhibited the trend of increasing first and then decreasing. Compared with PI-0, the tensile strength of PI-2 film increased from 85.71 to $106.02 \mathrm{MPa}$, which indicates the effect of TAPB on the tensile strength of PI. Such an improvement is ascribed to the fact that the addition of TAPB can effectively promote the connection between PI molecular chains, resulting in the inability of molecular chains to slip relative to

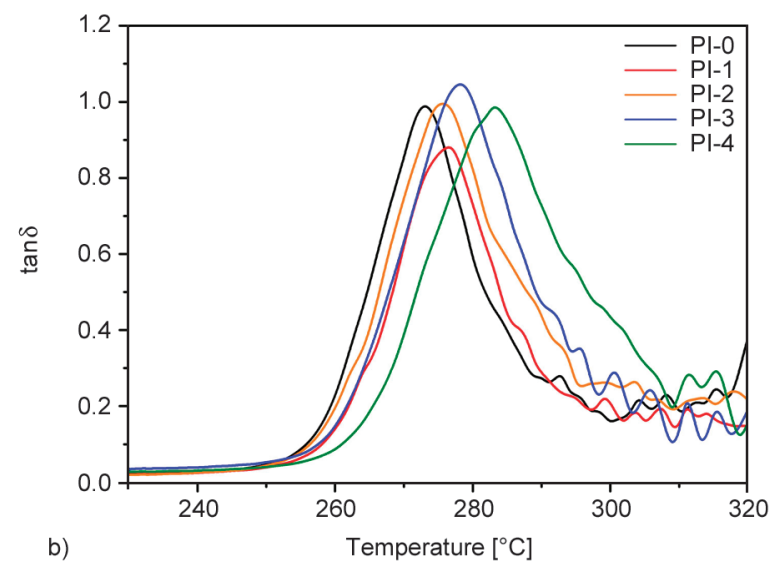

Figure 6. Dynamic mechanical analysis of PIs films. (a) Storage modulus, and (b) $\tan \delta$ curves. 


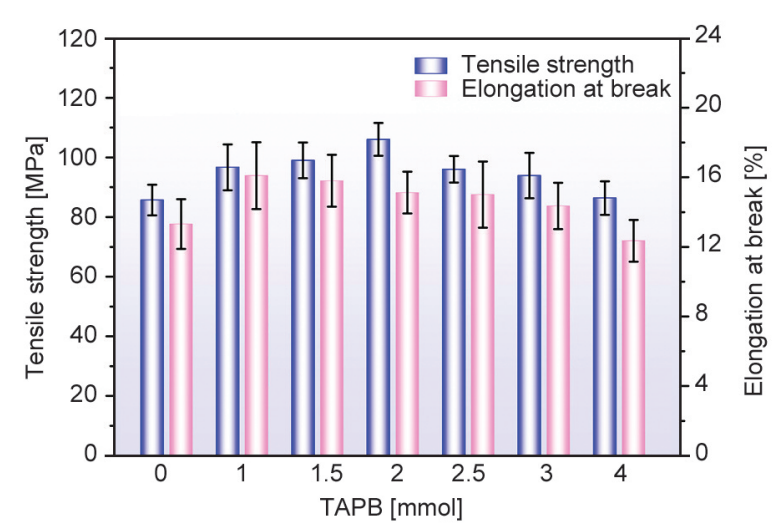

Figure 7. Tensile strength and elongation at break of PI films.

each other and the more compact structure of PI. However, when the addition of TAPB surpassed 2 mmol, the tensile strength showed a downward trend because the excessive crosslinked network chains tend to concentrate the stress on the local network chains, resulting in a significant reduction in the number of effective network chains. In addition, the elongation at the break of PI films decreased with the TAPB increasing due to the formation of a crosslinked structure, resulting in the increased rigidity of PI chains.

\section{Conclusions}

In this work, a series of branched micro-crosslink PI copolymer films were synthesized by introducing TPE-R, BAFL, 6FDA, and BPADA as the constitutional units, along with TAPB as the crosslinking monomer and branched center. The variation of thermal stability, hydrophobic properties, dielectric properties, and mechanical performance was dependent on the content of branched structures in PI molecular chains, and the branched micro-crosslink structure can be controlled by adding different content of TAPB. The result showed that the thermal stability of PIs was maintained at a high level and $T_{5}$ was higher than $527^{\circ} \mathrm{C}$. What's more, the contact angle of PI films with TAPB was increased from 72.9 to $95.1^{\circ}$, with the content of TAPB increased to $3 \mathrm{mmol}$. The absorption capacity of the PI films to UV light improved as the TAPB content increased. Moreover, the dielectric permittivity of PI films was significantly reduced by the introduction of TAPB, and the dielectric loss was also kept at a low level. The PI films reached their lowest dielectric permittivity value (2.47) under $1 \mathrm{MHz}$ at $0.2 \mathrm{mmol}$ of TAPB, and the dielectric loss exhibits a $10.3 \%$ reduction. It is attributed to the introduction of TAPB in an appropriate amount that can expand the space between the molecular chains while restricting the orientation of dipoles effectively to reduce the molecular polarizability, which also leads to the reduction of dielectric constant and loss. Compared with PI-0, the tensile strength of PI-2 film increased from 85.71 to 106.02 $\mathrm{MPa}$, which was ascribed to the fact that the addition of TAPB effectively promoted the connection between PI molecular chains and prevented chains from slipping relative to each other.

\section{Acknowledgements}

This work was supported by the Natural Science Foundation of Guangdong Province (2021A1515012425), the International Collaboration Programs of Guangdong Province (2020A0505100010), and the Overseas Famous Scholar Foundation of Guangdong Province (2020A1414010372).

\section{References}

[1] Zhang M., Xu P., Peng H., Qin F.: A rational design of core-shell-satellite structured $\mathrm{BaTiO}_{3}$ fillers for epoxybased composites with enhanced microwave dielectric constant and low loss. Composites Part B: Engineering, 215, 108764 (2021).

https://doi.org/10.1016/j.compositesb.2021.108764

[2] Liu F., Chen X., Hou J., Sun J., Fang Q.: A fluorinated thermocrosslinkable organosiloxane: A new low-k material at high frequency with low water uptake. Macromolecular Rapid Communications, 42, 2000600 (2021). https://doi.org/10.1002/Marc.202000600

[3] Qian C., Fan Z-G., Zheng W-W., Bei R-X., Zhu T-W., Liu S-W., Chi Z-G., Aldred M. P., Chen X-D., Zhang Y., Xu J-R.: A facile strategy for non-fluorinated intrinsic low-k and low-loss dielectric polymers: Valid exploitation of secondary relaxation behaviors. Chinese Journal of Polymer Science, 38, 213-219 (2020). https://doi.org/10.1007/s10118-020-2339-4

[4] Zhang F., Li J., Wang T., Huang C., Ji F., Shan L., Zhang G. P., Sun R., Wong C-P.: Fluorinated graphene/ polyimide nanocomposites for advanced electronic packaging applications. Journal of Applied Polymer Science, 138, 49801 (2021).

https://doi.org/10.1002/app.49801

[5] Wang Z., Zhang M., Han E., Niu H., Wu D.: Structureproperty relationship of low dielectric constant polyimide fibers containing fluorine groups. Polymer, 206, 122884 (2020).

https://doi.org/10.1016/j.polymer.2020.122884

[6] Zuo H-T., Gan F., Dong J., Zhang P., Zhao X., Zhang Q. H.: Highly transparent and colorless polyimide film with low dielectric constant by introducing meta-substituted structure and trifluoromethyl groups. Chinese Journal of Polymer Science, 39, 455-464 (2021). https://doi.org/10.1007/s10118-021-2514-2 
[7] Wu T., Dong J., Gan F., Fang Y., Zhao X., Zhang Q.: Low dielectric constant and moisture-resistant polyimide aerogels containing trifluoromethyl pendent groups. Applied Surface Science, 440, 595-605 (2018). https://doi.org/10.1016/j.apsusc.2018.01.132

[8] Cao X., Wen J., Song L., Liu X., He G.: Polyimide hollow glass microspheres composite films with low dielectric constant and excellent thermal performance. Journal of Applied Polymer Science, 138, 50600 (2021). https://doi.org/10.1002/app.50600

[9] Ma S., Wang Y., Min Z., Zhong L.: Nano/mesoporous polymers based low- $k$ dielectric materials: A review on methods and advances. Advances in Polymer Technology, 32, 21358 (2013). https://doi.org/10.1002/Adv.21358

[10] Chen Z., Liu S., Yan S., Shu X., Yuan Y., Huang H., Zhao J.: Overall improvement in dielectric and mechanical properties of porous graphene fluoroxide/polyimide nanocomposite films via bubble-stretching approach. Materials and Design, 117, 150-156 (2017).

https://doi.org/10.1016/j.matdes.2016.12.082

[11] Zhou H., Lei H., Wang J., Qi S., Tian G., Wu D.: Breaking the mutual restraint between low permittivity and low thermal expansion in polyimide films via a branched crosslink structure. Polymer, 162, 116-120 (2019). https://doi.org/10.1016/j.polymer.2018.12.033

[12] Han S., Li Y., Hao F., Zhou H., Qi S., Tian G., Wu D.: Ultra-low dielectric constant polyimides: Combined efforts of fluorination and micro-branched crosslink structure. European Polymer Journal, 143, 110206 (2021). https://doi.org/10.1016/j.eurpolymj.2020.110206

[13] Song N., Yao H., Ma T., Wang T., Shi K., Tian Y., Zhang B., Zhu S., Zhang Y., Guan S.: Decreasing the dielectric constant and water uptake by introducing hydrophobic cross-linked networks into co-polyimide films. Applied Surface Science, 480, 990-997 (2019). https://doi.org/10.1016/j.apsusc.2019.02.141

[14] Wu W., Zhao W., Gong X., Sun Q., Cao X., Su Y., Yu B., Li R. K. Y., Vellaisamy R. A. L.: Surface decoration of halloysite nanotubes with POSS for fire-safe thermoplastic polyurethane nanocomposites. Journal of Materials Science and Technology, 101, 107-117 (2022). https://doi.org/10.1016/j.jmst.2021.05.060

[15] Xu C., Gao Z., Guo Y., Shu M., Gao Y.: Study on insitu growth of polyhedral oligomeric silsesquioxane (POSS) layer on kapton surface and the properties of $\mathrm{SiO}_{2} / \mathrm{POSS}$ coatings. Colloids and Surfaces A: Physicochemical and Engineering Aspects, 595, 124720 (2020). https://doi.org/10.1016/j.colsurfa.2020.124720

[16] Deng G., Luo J., Liu S., Wang Y., Zong X., Wu Q., Xue S.: Low-temperature synthesis and gas transport properties of novel contorted hyperbranched polyimides containing binaphthyl structures. Separation and Purification Technology, 248, 117088 (2020).

https://doi.org/10.1016/j.seppur.2020.117088
[17] Zhang P., Zhang K., Chen X., Dou S., Zhao J., Li Y. Mechanical, dielectric and thermal properties of polyimide films with sandwich structure. Composite Structures, 261, 113305 (2021).

https://doi.org/10.1016/j.compstruct.2020.113305

[18] Yang Y., Xia J., Ding Z., Zheng Y., Ding S., Shen Y.: Synthesis and resistive switching characteristics of polyimides derived from 2,7-aryl substituents tetraphenyl fluorene diamines. European Polymer Journal, 108, 8597 (2018).

https://doi.org/10.1016/j.eurpolymj.2018.08.040

[19] He Z., Xie J., Liao Z., Ma Y., Zhang M., Zhang W., Yue H., Gao X.: Hierarchical porous structure contained composite polyimide film with enhanced dielectric and water resistance properties for dielectric material. Progress in Organic Coatings, 151, 106030 (2021). https://doi.org/10.1016/j.porgcoat.2020.106030

[20] Ma Y., He Z., Liao Z., Xie J., Yue H., Gao X.: Facile strategy for low dielectric constant polyimide/ silsesquioxane composite films: Structural design inspired from nature. Journal of Materials Science, 56, 7397-7408 (2021).

https://doi.org/10.1007/s10853-021-05771-y

[21] Chen W., Zhou Z., Yang T., Bei R., Zhang Y., Liu S., Chi Z., Chen X., Xu J.: Synthesis and properties of highly organosoluble and low dielectric constant polyimides containing non-polar bulky triphenyl methane moiety. Reactive and Functional Polymers, 108, 71-77 (2016). https://doi.org/10.1016/j.reactfunctpolym.2016.04.011

[22] Huang X., Wang J., Li Q., Lin J., Wang Z.: Impact of the phenyl thioether contents on the high frequency dielectric loss characteristics of the modified polyimide films. Surface and Coatings Technology, 360, 205-212 (2019).

https://doi.org/10.1016/j.surfcoat.2018.12.111

[23] Wang C-Y., Chen W-T., Xu C., Zhao X-Y., Li J.: Fluorinated polyimide/POSS hybrid polymers with high solubility and low dielectric constant. Chinese Journal of Polymer Science, 34, 1363-1372 (2016).

https://doi.org/10.1007/s10118-016-1845-x

[24] Chen Z., Zhou Y., Wu Y., Liu S., Huang H., Zhao J.: Fluorinated polyimide with polyhedral oligomeric silsesquioxane aggregates: Toward low dielectric constant and high toughness. Composites Science and Technology, 181, 107700 (2019).

https://doi.org/10.1016/j.compscitech.2019.107700

[25] Liao W-H., Yang S-Y., Hsiao S-T., Wang Y-S., Li S-M., Ma C-C. M., Tien H-W., Zeng S-J.: Effect of octa (aminophenyl) polyhedral oligomeric silsesquioxane functionalized graphene oxide on the mechanical and dielectric properties of polyimide composites. ACS Applied Materials and Interfaces, 6, 15802-15812 (2014). https://doi.org/10.1021/am504342j 
[26] Li X., Zhang P., Dong J., Gan F., Zhao X., Zhang Q.: Preparation of low- $\kappa$ polyimide resin with outstanding stability of dielectric properties versus temperature by adding a reactive Cardo-containing diluent. Composites Part B: Engineering, 177, 107401 (2019).

https://doi.org/10.1016/j.compositesb.2019.107401

[27] Zhu T., Yu Q., Zheng W., Bei R., Wang W., Wu M., Liu S., Chi Z., Zhang Y., Xu J.: Intrinsic high-k-low-loss dielectric polyimides containing ortho-position aromatic nitrile moieties: Reconsideration on Clausius-Mossotti equation. Polymer Chemistry, 12, 2481-2489 (2021). https://doi.org/10.1039/d1py00084e

[28] Li X., Liu T., Jiao Y., Dong J., Gan F., Zhao X., Zhang Q.: Novel high-performance poly(benzoxazole-coimide) resins with low dielectric constants and superior thermal stabilities derived from thermal rearrangement of ortho-hydroxy polyimide oligomers. Chemical Engineering Journal, 359, 641-651 (2019).

https://doi.org/10.1016/j.cej.2018.11.175
[29] Birtane H., Esmer K., Madakbas S., Kahraman M. V. Structural and dielectric properties of POSS reinforced polyimide nanocomposites. Journal of Macromolecular Science Part A: Pure and Applied Chemistry, 56, 245 252 (2019).

https://doi.org/10.1080/10601325.2019.1565546

[30] Zhou H., Wei D., Fan Y., Chen H., Yang Y., Yu J., Jin L.: Dielectric properties of polyimide $/ \mathrm{SiO}_{2}$ hollow spheres composite films with ultralow dielectric constant. Materials Science and Engineering B: Advanced Functional Solid-State Materials, 203, 13-18 (2016). https://doi.org/10.1016/j.mseb.2015.10.003 